\title{
Attitude towards and Interest in Dog-Assisted Interventions of Students in Higher Education
}

\author{
Cathrin Rothkopf, Theresa Stark, Silke Schworm
}

Department of pedagogy, University of Regensburg, Germany.

\begin{abstract}
The mental health of students is a critical issue facing institutions of higher education, as a majority of college and university students report suffering from stress and anxiety. Studies have shown that interacting with animals can enhance the mental health. Consequently, animal-assisted interventions can be used to cover the concerns of students. This study evaluated German university students' attitude towards dogs, animal-assisted interventions and their interest in its use at their own university. Additionally, possible predictors were investigated. Another aim was the validation of the questionnaire. 560 university students answered a questionnaire consisting of the Coleman Dog Attitude Scale (C-DAS), a modification of the Attitude Towards Animal-Assisted Therapy Scale and a translated and modified version of the Cuestionario de Actitudes ante las Intervenciones Asistidas por Perros (CAINTAP). Results showed a slightly positive attitude towards dogs, animal-assisted interventions and interest in its use at the university. Furthermore, students'course of studies and sex have proven to be predictors. Thus, especially female students of educational science would welcome an implementation of animal-assisted interventions at the university. The questionnaire showed high quality with a Cronbach's alpha $\alpha$ $=.936$.
\end{abstract}

Keywords: Animal-Assisted Intervention; Higher Education; Attitude; Interest 


\section{Introduction}

Going to college or university is a new chapter in any person's life. There are a lot of things changing and new challenges appearing. Students can experience elevated stress levels and anxiety due to new teaching methods, academic pressure, external and internal expectations, time and financial management, new social environment and geographic locations (e.g. Miczo, Miczo \& Johnson, 2006; Misra \& McKean, 2000). As a consequence, a lot of students suffer from mental health problems. According to an American College Health Association survey of more than 63,000 students in spring 2017, 87 percent of students reported feeling overwhelmed by their workload, 84 percent felt exhausted, 61 percent felt overwhelming anxiety and about 45 percent rated their overall level of stress as "more than average stress". An increased stress level in students in higher education was found in Germany, too. According to a study of the health insurance company AOK in 2016, the stress experience of students is still more distinctive than the one of the average of employees (Herbst et al., 2016), which is in line with the findings of Eskin et al. (2016), who reported a higher psychological distress in university students than in the general population. The stress level increases upon entry to university and does not decrease throughout their time there (Bewick et al., 2010).

To keep up with the increasing need for counseling service and to address the concerns of college and university students, finding new alternative ways to help has become paramount. One service that is increasingly used to meet the needs of students are animalassisted interventions. An investigation by Haggerty and Mueller (2017) found that 62 percent of the surveyed universities in the United States already have animal-assisted programs and the majority of them use dogs. In animal-assisted programs commonly a group of students gets the chance to interact with therapy dogs and their handlers in dropin-sessions. Previous research has revealed that those interventions can, amongst others, reduce students' stress (e.g. Binfet, 2017; Ward-Griffin et al., 2018), anxiety (e.g. Grajfoner et al., 2017; Jarolmen \& Patel, 2018), homesickness and can increase their satisfaction with life and connectedness to campus (Binfet \& Passmore, 2016). Nonetheless, animal-assisted interventions have not been used at German universities thus far. As a consequence, the aim of this study was to examine German students'attitude towards dogs, animal-assisted interventions and interest in its use at their own university. To gain more information, possible predictors were investigated additionally. It was hypothesized that:

1) German students have a positive attitude towards dogs, animal-assisted interventions and its use at their home university.

2) Sex and course of studies influence students' attitude towards dogs, animal-assisted interventions and its use at their home university.

3) Age has no influence on students' attitude towards dogs, animal-assisted interventions and its use at their home university. 
Furthermore, the created questionnaire should be validated.

\section{Attachment Theory}

The relationship between animals and humans, and their effect on them, can be explained by the application of the attachment theory. The attachment theory (Bowlby, 1973, 1980, 1982) is an empirically supported framework that explains how close relationships influence emotion regulation, mental health, and psychological growth. It can be applied to relationships that meet four criteria (e.g., Hazan \& Shaver, 1987; Hazan \& Zeifman, 1994): proximity maintenance, safe haven, secure base and separation distress. As pets often meet these four prerequisites for an attachment figure/object, the human-pet bond can be viewed as an attachment relationship (Zilcha-Mano, Mikulincer \& Shaver, 2011). Additionally, there may be secondary or context-specific attachment figures. Unlike primary attachment relationships, they might be more time-limited and situation-dependent. For example, therapists in therapeutic settings (Mallinckrodt, Gantt \& Coble, 1995) can be actual or potential sources of comfort and support. According to Triebenbacher (1998), behaviors such as following, smiling toward, holding, and touching are evident in the reciprocal relationship between child and attachment figure, which can be observed in interactions between humans and animals, too. In summary, animals in visitation programs might also serve as attachment figures/objects and offer the benefits derived from them.

\section{Methods}

\subsection{Participants}

560 students of the University of Regensburg in Germany $\left(N_{f}=408, N_{m}=144, N_{o}=8\right)$, with a mean age of $20.90(S D=2.742$, range 16-40) participated. The course of studies varied between teaching profession for primary schools "Grundschule" $(N=160)$, teaching profession for elementary school "Mittelschule" $(N=72)$, teaching profession for secondary school "Realschule" $(N=41)$, teaching profession for grammar school "Gymnasium" ( $N=129)$, educational science "EWS" $(N=105)$, and single others like media studies.

\subsection{Questionnaire}

A questionnaire was created based on the Coleman Dog Attitude Scale (C-DAS), the Attitude Towards Animal-Assisted Therapy Scale and a translated version of the Cuestionario de Actitudes ante las Intervenciones Asistidas por Perros (CAINTAP). Furthermore, demographic information was gathered at the beginning of the questionnaire. 
Demographic Information. Demographic information was asked to gain knowledge of students'sex, age, course of studies and semester.

Coleman Dog Attitude Scale (C-DAS). The Coleman Dog Attitude Scale assesses attitudes towards dogs. It is a 24-item self-report measure and has shown to be reliable and valid with a Cronbach's alpha ranging from 0.98 to 0.99. (Coleman, Green, Garthe, Worthington, Barker \& Ingram, 2016).

Attitude Towards Animal-Assisted Therapy Scale. Consisting of 19-items, the Attitude Towards Animal-Assisted Therapy Scale measures the attitude towards animal-assisted therapy. The questionnaire showed a high internal consistency with a Cronbach's alpha $\alpha=$ 0.85 (Hightower, 2010)

Cuestionario de Actitudes ante las Intervenciones Asistidas por Perros (CAINTAP). The Cuestionario de Actitudes ante las Intervenciones Asistidas por Perros (CAINTAP) consists of 22-items, measuring the attitude towards dog-assisted interventions - perceived benefits and fears. It is separated in two factors, positive and negative attitude, both with Cronbach's alphas $\alpha>0,87$ (López-Cepero Borrego, Perea-Mediavilla, Tejada Roldán \& SarasolaSánchez-Serrano, 2015)

Due to its use at the university, some questions had to be modified for this context. The resulting questionnaire consisted of 24-items measuring students'attitude towards dogs and 20 -items measuring their attitude towards animal-assisted interventions on a 7-point scale with $1=$ strongly disagree and $7=$ strongly agree, and closing 22-items measuring their attitude towards dog-assisted interventions at their home university on a 5-point scale with $1=$ strongly disagree and $5=$ strongly agree.

\subsection{Procedure}

The questionnaire was handed out to students at the beginning of different lectures. They were told, that this study was part of a thesis and participating was absolutely voluntary and anonymous. After about 15 minutes, the completed questionnaires were collected again.

\section{Results}

The program SPSS was used to analyze the data. A total of 548 valid questionnaires were obtained.

\subsection{Validation of the Questionnaire}

Principal component analysis (PCA) showed - analogical to the factor analyses carried out by the creators of the three origin questionnaires - a one-factor solution for the modified CDAS (MC-DAS) and Attitude Towards Animal-Assisted Therapy Scale (MATAATS), 
while the modified CAINTAP can be separated into two factors. These were called "benefits" and "fears". Cronbach's alpha showed for MC-DAS, MATAATS and the factor "benefits" high results with $\alpha>.90$, and a Cronbach's alpha $\alpha=.871$ for the factor "fears".

\subsection{Attitude of German Students}

German students showed a more positive attitude towards dogs $(M=4.72, S D=1.65)$ and animal-assisted interventions $(M=4.71, S D=.98)$. Furthermore, they rather see benefits (e.g. dogs would distract people from their sorrows; dog-assisted pedagogy would help participants to relax; dog-assisted pedagogy would make the university a happier place) in its use at their university $(M=3.46, S D=.67)$ than fears $(M=2.92, S D=.76)($ e.g. $\operatorname{dogs}$ would bark at the university; it is possible that the dogs worsen certain respiratory problems; dog allergies would be a problem).

\subsection{Influences on Student's Attitude}

Results showed that students' sex had a significant, but small effect on their attitude towards dogs $\left(\eta^{2}=.011\right)$, animal-assisted interventions $\left(\eta^{2}=.015\right)$ and the benefits they see in its use at their home university $\left(\eta^{2}=.019\right)$. Women proved to be a little more in favour of it than men. Only their fears were not affected by their sex $\left(\eta^{2}=.004\right)$. In addition, there were differences in students' attitude towards $\operatorname{dogs}\left(\mathrm{F}_{(4,502)}=2.535, \mathrm{p}<0.05\right)$ and the benefits they see in the use of dog-assisted interventions at their home university $\left(\mathrm{F}_{(4,497)}=\right.$ $2.878, \mathrm{p}<0.05$ ) due to their course of studies (figure 1). Their attitude towards animalassisted interventions and their fears, however, were not affected by it. Furthermore, their age did not have a significant influence on students' attitudes and interest $(p>.05)$.
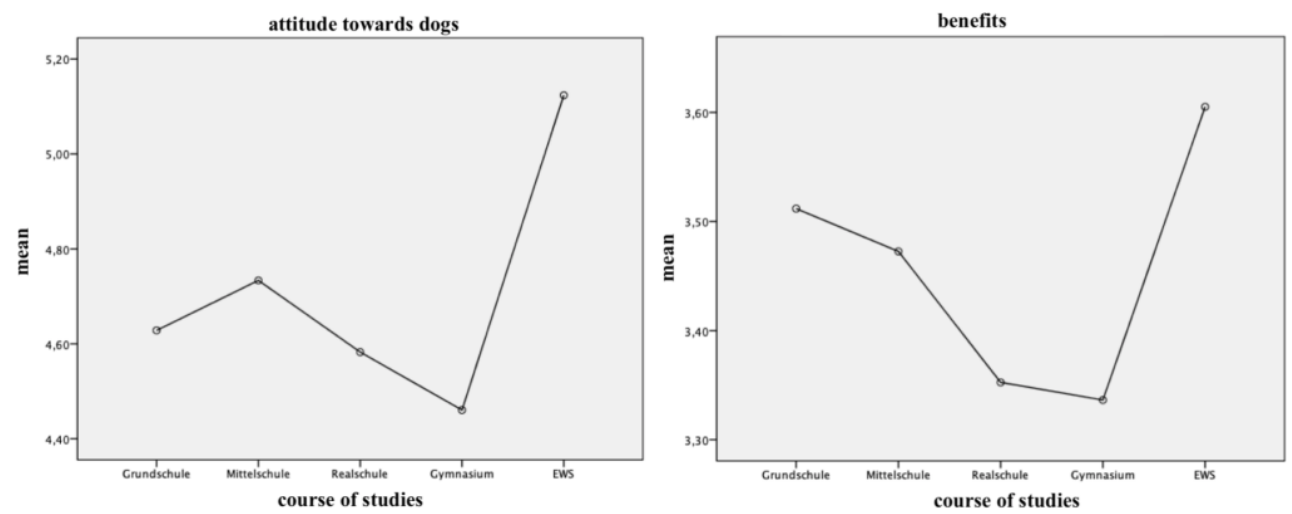

Figure 1. Differences in students' attitude due to their course of studies. 


\section{Discussion}

The aim of this study was to assess German students' attitude to and interest in dog-assisted interventions. The holistic effect animals have on human beings in a diverse assortment of settings has been documented in a wide range of research (e.g. Halm, 2008; Kaminski, Pellino \& Wish, 2002) and is one reason for its current use in pedagogical, psychological and therapeutic interventions. Due to the increasing need for counseling service of college and university students and to address their concerns, animal-assisted interventions could be used. As dogs can provide social and emotional support, dog-assisted interventions hold potential to strengthen students' mental health.

The findings of this study show that German students have a slightly positive attitude towards dogs, animal-assisted interventions and interest in its use at the university. They see more benefits in its use than fears. Consequently, the implementation of dog-assisted interventions could be profitable for German universities. Nonetheless, students' fears about its use need to be noticed and preventive measures have to be taken. In addition, students' course of studies and sex have proven to be predictors. Female students and students of educational science showed to have a more positive attitude towards and interest in its use. Furthermore, the questionnaire showed high quality with a Cronbach's alpha $\alpha=$ .936. This result supports the use of this questionnaire to gain information about students' attitude to and interest in dog-assisted interventions at their home university.

\section{Limitations and Future Directions}

Despite the best of intentions, this study was not without limitations. The majority of the participants were female, the courses of studies were not equally distributed and limited to courses in the liberal arts. Future research should investigate a wider range of courses of studies and make sure that the sample is equally distributed. Furthermore, it should be tested, if the number of items can be reduced, as the survey still is a little time-consuming.

\section{Conclusion}

As institutions of higher education need to look for innovative ways to support the social and emotional wellbeing of their students, dog-assisted interventions are gaining popularity. Nonetheless, German universities have not yet implemented them. This might be due to the uncertainty if students are actually interested in them. The created questionnaire could provide information about students' attitude towards and interest in dog-assisted interventions at their home university. It consists of 66 items and has proven to be applicable to measure students' attitude towards and interest in dog-assisted interventions. 
In addition, the results of this study have shown that German students have a slightly positive attitude towards and interest in dog-assisted interventions at their home university.

\section{References}

American College Health Association (2017). American College Health AssociationNational College Health Assessment II: Reference Group Executive Summary Spring 2017. Hanover, MD: American College Health Association. Retrieved May 15, 2018 from http://www.acha-ncha.org/docs/NCHAII_SPRING_2017_REFERENCE_GROUP_EXECUTIVE_SUMMARY.pdf

Bewick, B., Koutsopoulou, G., Miles, J., Slaa, E., \& Barkham, M. (2010). Changes in undergraduate students' psychological well-being as they progress through university. Studies in Higher Education, 35(6), 633-645. https://doi.org/10.1080/03075070903216643

Binfet, J.-T. (2017). The Effects of Group-Administered Canine Therapy on University Students' Wellbeing: A Randomized Controlled Trial. Anthrozoös, 30(3), 397-414. https://doi.org/10.1080/08927936.2017.1335097

Binfet, J.-T., \& Passmore, H.-A. (2016). Hounds and Homesickness: The Effects of an Animal-assisted Therapeutic Intervention for First-Year University Students. Anthrozoös, 29(3), 441-454. https://doi.org/10.1080/08927936.2016.1181364

Bowlby, J. (1973). Attachment and loss, Vol. 2: Separation, anxiety, and anger. New York: Basic Books.

Bowlby, J. (1980). Attachment and loss, Vol. 3: Sadness and depression. New York: Basic Books.

Bowlby, J. (1982). Attachment and loss: Vol. 1: Attachment (2nd ed.). New York: Basic Books.

Coleman, J. A., Green, B., Garthe, R. C., Worthington, E. L., Barker, S. B., \& Ingram, K. M. (2016). The Coleman Dog Attitude Scale (C-DAS): Development, refinement, validation, and reliability. Applied Animal Behaviour Science, 176, 77-86. https://doi.org/10.1016/j.applanim.2016.01.003

Eskin, M., Sun, J.-M., Abuidhail, J., Yoshimasu, K., Kujan, O., Janghorbani, M., et al. (2016). Suicidal Behavior and Psychological Distress in University Students: A 12 nation Study. Archives of Suicide Research, 20(3), 369-388. https://doi.org/10.1080/13811118.2015.1054055

Grajfoner, D., Harte, E. Potter, L., \& McGuigan, N. (2017). The Effect of Dog-Assisted Intervention on Student Well-Being, Mood, and Anxiety. International Journal of Environmental Research and Public Health, 14(5), 483. https://doi.org/10.3390/ijerph14050483

Haggerty, J. M., \& Mueller, M. K. (2017). Animal-assisted Stress Reduction Programs in Higher Education. Innovative Higher Education, 42(5-6), 379-389. https://doi.org/10.1007/s10755-017-9392-0

Halm, M. A. (2008). The healing power of the human-animal connection. American Journal of Critical Care, 17(4), 373-376. 
Hazan, C., \& Shaver, P. (1987). Romantic love conceptualized as an attachment process. Journal of Personality and Social Psychology, 52(3), 511-524. https://doi.org/10.1037/0022-3514.52.3.511

Hazan, C., \& Zeifman, D. (1994). Sex and the psychological tether. In K. Bartholomew \& D. Perlman (Eds.), Advances in personal relationships, Vol.5. Attachment processes in adulthood (pp. 151-177). London: Jessica Kingsley.

Herbst, U., Voeth, M., Eidhoff, A. T., Müller, M., \& Stief, S. (2016). Studierendenstress in Deutschland - eine empirische Untersuchung. Berlin: AOK-Bundesverband.

Hightower, R. M. (2010). Assessment of occupational therapists' attitudes and knowledge of animal-assisted therapy. Master's and Doctoral Projects. Paper 189. Retrieved from: https://pdfs.semanticscholar.org/eace/1933582f4dab6b4ec98d682f0bbe55806260.pdf

Jarolmen, J., \& Patel, G. (2018). The Effects of Animal-Assisted Activities on College Students Before and After a Final Exam. Journal of Creativity in Mental Health, 1-11. https://doi.org/10.1080/15401383.2018.1425941

Kaminski, M., Pellino, T., \& Wish, J. (2002). Play and Pets: The Physical and Emotional Impact of Child-Life and Pet Therapy on Hospitalized Children. Children's Health Care, 31(4), 321-335. https://doi.org/10.1207/S15326888CHC3104_5

López-Cepero Borrego, J., Perea-Mediavilla, M. A., Tejada Roldán, A., \& SarasolaSánchez-Serrano, J. L. (2015). Validación del Cuestionario de Actitudes ante las Intervenciones Asistidas por Perros (CAINTAP) en Estudiantes Universitarios del Sur de España: Beneficios y Temores Percibidos. Alternativas. Cuadernos de Trabajo Social, (22). https://doi.org/10.14198/ALTERN2015.22.07

Mallinckrodt, B., Gantt, D. L., \& Coble, H. M. (1995). Attachment patterns in the psychotherapy relationship: Development of the Client Attachment to Therapist Scale. Journal of Counseling Psychology, 42(3), 307-317. https://doi.org/10.1037/0022$\underline{0167.42 .3 .307}$

Miczo, N., Miczo, L. A., \& Johnson, M. (2006). Parental Support, Perceived Stress, and Illness-Related Variables Among First-Year College Students. Journal of Family Communication, 6(2), 97-117. https://doi.org/10.1207/s15327698jfc0602_1

Misra, R., \& McKean, M. (2000). College Students' Academic Stress and its Relation to Their Anxiety, Time Management, And Leisure Satisfaction. American Journal Of Health Studies, 16(1), 41-51.

Triebenbacher, S. L. (1998). Pets as Transitional Objects: Their Role in Children's Emotional Development. Psychological Reports, 82(1), 191-200. https://doi.org/10.2466/pr0.1998.82.1.191

Ward-Griffin, E., Klaiber, P., Collins, H. K., Owens, R. L., Coren, S., \& Chen, F. S. (2018). Petting away pre-exam stress: The effect of therapy dog sessions on student well-being. Stress and Health, 34(3), 468-473. https://doi.org/10.1002/smi.2804

Zilcha-Mano, S., Mikulincer, M., \& Shaver, P. R. (2011). An attachment perspective on human-pet relationships: Conceptualization and assessment of pet attachment orientations. Journal of Research in Personality, 45(4), 345-357. https://doi.org/10.1016/j.jrp.2011.04.001 